\title{
Advances and limitations of atmospheric boundary layer observations with GPS occultation over southeast Pacific Ocean
}

\author{
F. Xie ${ }^{1,2}$, D. L. Wu ${ }^{2, *}$, C. O. Ao ${ }^{2}$, A. J. Mannucci ${ }^{2}$, and E. R. Kursinski ${ }^{3, * *}$ \\ ${ }^{1}$ Joint Institute for Regional Earth System Science and Engineering (JIFRESSE), University of California, Los Angeles, \\ California, USA \\ ${ }^{2}$ Jet Propulsion Laboratory, California Institute of Technology, Pasadena, California, USA \\ ${ }^{3}$ Department of Atmospheric Sciences, University of Arizona, Tucson, Arizona, USA \\ * now at: NASA/Goddard Space Flight Center, Greenbelt, Maryland, USA \\ *** now at: Broad Reach Engineering, Golden, Colorado, USA \\ Correspondence to: F. Xie (fxie@jifresse.ucla.edu)
}

Received: 17 July 2011 - Published in Atmos. Chem. Phys. Discuss.: 12 August 2011

Revised: 23 January 2012 - Accepted: 6 January 2012 - Published: 19 January 2012

\begin{abstract}
The typical atmospheric boundary layer (ABL) over the southeast (SE) Pacific Ocean is featured with a strong temperature inversion and a sharp moisture gradient across the ABL top. The strong moisture and temperature gradients result in a sharp refractivity gradient that can be precisely detected by the Global Positioning System (GPS) radio occultation (RO) measurements. In this paper, the Constellation Observing System for Meteorology, Ionosphere \& Climate (COSMIC) GPS RO soundings, radiosondes and the high-resolution ECMWF analysis over the SE Pacific are analyzed. COSMIC RO is able to detect a wide range of $\mathrm{ABL}$ height variations $(1-2 \mathrm{~km})$ as observed from the radiosondes. However, the ECMWF analysis systematically underestimates the ABL heights. The sharp refractivity gradient at the ABL top frequently exceeds the critical refraction (e.g., $-157 \mathrm{~N}$-unit $\mathrm{km}^{-1}$ ) and becomes the so-called ducting condition, which results in a systematic RO refractivity bias (or called $N$-bias) inside the ABL. Simulation study based on radiosonde profiles reveals the magnitudes of the $N$-biases are vertical resolution dependent. The $N$-bias is also the primary cause of the systematically smaller refractivity gradient (rarely exceeding $-110 \mathrm{~N}$-unit $\mathrm{km}^{-1}$ ) at the $\mathrm{ABL}$ top from RO measurement. However, the $N$-bias seems not affect the ABL height detection. Instead, the very large RO bending angle and the sharp refractivity gradient due to ducting allow reliable detection of the ABL height from GPS RO. The seasonal mean climatology of ABL heights derived from a nine-month composite of COSMIC RO soundings over the SE Pacific reveals significant differences from the ECMWF analysis. Both show an increase of ABL height from the shal-
\end{abstract}

low stratocumulus near the coast to a much higher trade wind inversion further off the coast. However, COSMIC RO shows an overall deeper $\mathrm{ABL}$ and reveals different locations of the minimum and maximum ABL heights as compared to the ECMWF analysis. At low latitudes, despite the decreasing number of COSMIC RO soundings and the lower percentage of soundings that penetrate into the lowest 500-m above the mean-sea-level, there are small sampling errors in the mean ABL height climatology. The difference of ABL height climatology between COSMIC RO and ECMWF analysis over SE Pacific is significant and requires further studies.

\section{Introduction}

The atmospheric boundary layer (ABL) over the southeast (SE) Pacific Ocean is characterized by a strong temperature inversion layer across the ABL top. Persistent shallow stratocumulus $(\mathrm{Sc}$ ) cloud decks trapped below the $\mathrm{ABL}$ inversion play an important role in cloud-climate feedback processes because of its radiative cooling effect (e.g., Randall et al., 1984; Slingo, 1990; Klein and Hartmann, 1993; Ma et al., 1996; Bony and Dufresne, 2005; Clement et al., 2009). Lack of understanding and observations of complicated ABL processes (e.g., cloud radiative cooling, entrainment, turbulent mixing, ocean-atmosphere coupling) leads to great model uncertainties in weather and climate predictions (e.g., Randall et al., 1998; Zeng et al., 2004; Palm et al., 2005; Jordan et al., 2010). Observations of thermodynamic structure of the $\mathrm{ABL}$ over the open oceans are limited in space 
and time to ground-based measurements over islands, ship soundings and several field campaigns. Conventional passive microwave or infrared satellite sounders do not have a sufficient vertical resolution to resolve ABL vertical structures, especially the thin transition layer across the ABL inversion layer. Several satellite measurements have been used to indirectly infer the ABL height through aerosol layer or cloudtop-height observations, which could serve as good tracers for $\mathrm{ABL}$ top over the well-mixed boundary layer regime (e.g., stratocumulus-topped ABL). The Cloud-Aerosol Lidar and Infrared Pathfinder Satellite Observations (CALIPSO) lidar provides high precision height measurements of aerosol and low cloud layers (e.g., Wu et al., 2008). The Multiangle Imaging SpectroRadiometer (MISR) on Terra satellite can retrieve the cloud-top-height (CTH) using a stereophotogrammetric technique (e.g., Garay et al., 2008; Harshvardhan et al., 2009). Cloud-top-temperature (CTT) measurements from the geostationary or polar-orbiting satellites (e.g., Moderate Resolution Imaging Spectroradiometer, MODIS) through the infrared channel are also used for CTH retrieval with supplemental information of the vertical temperature structures (Wood and Bretherton, 2004; Zuidema et al., 2009). Nonetheless, all the above methods rely on the detection of ABL tracers (e.g., aerosol or clouds) and encounter significant challenges over the broken cloud (e.g., trade cumulus) or clear-sky regions. Also, the requirement for apriori meteorology information makes the MODIS CTH retrieval somewhat model dependent.

As a promising technique for profiling the shallow ABL, Constellation Observing System for Meteorology Ionosphere and Climate (COSMIC) radio occultation (RO) observations ( $\sim 2000$ daily profiles, available since April 2006) can measure ABL properties with global coverage, high vertical resolution ( $200-\mathrm{m}$ in the lower troposphere) and cloudpenetrating capability. It is important to note that the implementation of the open-loop tracking technique on the COSMIC RO receivers significantly improves the quality of RO soundings in the moist ABL, as compared with the early GPS RO missions that used phase-locked loop (PLL) tracking technique (Sokolovskiy 2001; Ao et al., 2009). Several studies have demonstrated the values of RO soundings in detecting the ABL height (e.g., Sokolovskiy et al., 2006; Sokolovskiy et al., 2007; Ao et al., 2008; Basha and Ratnam, 2009; Guo et al., 2011; Ao et al., 2012). However, probing the ABL interior with $\mathrm{RO}$ remains to be challenging. One of the critical problems is the systematic negative refractivity biases ( $N$-bias) in RO sounding profiles, which is often pronounced over the subtropical eastern oceans (Xie et al., 2010a), where the persistent sharp temperature and moisture gradient at the ABL top often results in the so-called ducting (or super-refraction) conditions (e.g., von Engeln and Teixeira, 2004; Lopez, 2009). In particular, over the SE Pacific, the overall quality and the scientific value of the RO soundings inside the ABL are yet to be explored.

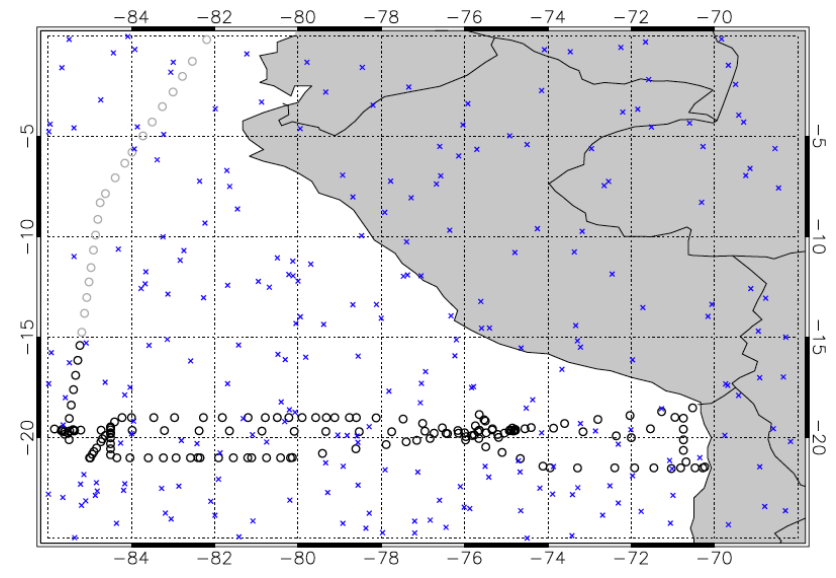

Fig. 1. Map of the ship-borne radiosonde (circle) and COSMIC RO (cross) sounding locations during VOCALS-REx field campaign from 20 October to 1 December 2008.

In this study, we analyzed the quality of COSMIC RO soundings in the SE Pacific by comparing the ABL top height measurements with those from the VAMOS Ocean-CloudAtmosphere-Land Study Regional Experiment (VOCALSREx) radiosonde (Wood et al., 2011) and the high-resolution European Centre for Medium-Range Weather Forecasts (ECMWF) analysis data. The paper is organized as follows: Sect. 2 describes the datasets used in this study, followed by the methodology and validation results in Sect. 3; Sect. 4 compares several key ABL parameters among COSMIC RO, VOCALS radiosonde observations and ECMWF analysis; Sect. 5 presents a seasonal mean ABL height climatology as well as the transect along $\sim 20^{\circ} \mathrm{S}$ derived from COSMIC RO and ECMWF analysis; Sect. 6 discusses advances and limitations of current RO soundings for ABL study; Finally, conclusions and future work are given in Sect. 7.

\section{Data description}

This study focuses on GPS RO boundary layer measurements over the SE Pacific (Fig. 1) where the VOCALS-REx field campaign took place during 20 October-1 December 2008 (Wood et al., 2011). The radiosondes collected from research cruises along the $20^{\circ} \mathrm{S}$ transect over SE Pacific in October 2006 and 2007 are also analysed (de Szoeke et al., 2010). The launch locations of the VOCALS radiosondes from NOAA research vessel (R/V Ronald H. Brown) and the COSMIC RO soundings during the campaign period are shown. A total of 213 radiosondes (10-m vertical sampling) were obtained at a 4-h interval. The COSMIC RO soundings are provided by Jet Propulsion Laboratory (JPL), available at http://gnenesis.jpl.nasa.gov (e.g., Hajj et al., 2002; Ao et al., 2009). The spatial and temporal sampling of COSMIC RO soundings is described in Sect. 5. The refractivity retrieval is reported as a function 
of geometric height above mean-sea-level (a.m.s.l.), and the bending angle is reported as a function of impact parameter, which is the product of refractive index and the local curvature radius at the tangent point. The detailed description of GPS RO occultation technique has been described in earlier studies (e.g., Kursinski et al., 1997; Anthes et al., 2008 etc.). Although RO soundings could potentially achieve $\sim 60 \mathrm{~m}$ vertical resolution (Goburnov, 2004), the resolution of JPL bending angle and refractivity profiles in the lower troposphere is limited by a $\sim 200$-m filter applied in the standard retrieval (similarly for the other RO data centers, e.g., Ho et al., 2009). Since the marine ABL is the main focus of this paper, only RO profiles that penetrate below m.s.l. $=0.5 \mathrm{~km}$ are used. This screening eliminates almost all RO profiles over the continents. We also examine the high-resolution ECMWF global analysis data (TL799L91), which have a horizontal resolution of $\sim 25 \mathrm{~km}\left(0.25^{\circ}\right.$ latitude $\times 0.25^{\circ}$ longitude) with 91 vertical layers from the surface to $0.01 \mathrm{hPa}$ (Bauer et al. 2006). The ECMWF six-hourly outputs (00:00/06:00/12:00/18:00 Z) have 17 unevenly-spaced layers below $800 \mathrm{hPa}(\sim 2 \mathrm{~km})$, with denser sampling near the surface. The vertical sample interval is $\sim 200$-m between 900 and $800 \mathrm{hPa}$, decreasing to $\sim 40-\mathrm{m}$ near the surface.

The ECMWF assimilation has incorporated the COSMIC RO soundings in its analysis (Healy, 2008). However, ECMWF does not assimilate the RO profiles below the ducting layer at the ABL top (Poli et al., 2010), which is frequently seen in the analysis over subtropical eastern oceans, especially over SE Pacific (e.g., von Engeln and Teixeira, 2004; Lopez, 2009). Also the VOCALS radiosondes are not assimilated into the analysis. Therefore, to large extent, the $\mathrm{RO}$, the radiosonde and the analysis data can be considered as independent measurements in the ABL.

\section{Methodology and validation}

Two important ABL parameters are analyzed here, i.e., the ABL top height and the refractivity gradient near the ABL top. The ABL height is generally marked as a transition height with a strong temperature inversion and a sharp moisture gradient. It is a key parameter to characterize the ABL, which is determined by the vertical scale of turbulent eddies and controls flux exchanges among turbulent mixing, heat and moisture in the ABL. It also depends on dynamic conditions of the underlying ocean surface and the free troposphere. The inversion strength, i.e., the temperature gradient across the thin transition layer (100-200 m thick) at the ABL top, is a measure of the stability of the transition layer. The inversion strength along with turbulent kinetic energy (TKE) controls the entrainment rate, a critical cloud dynamic parameter that determines the magnitude of warming and drying of the ABL by mixing its air with the free troposphere (Lilly 1968; Deardorff, 1976). The ABL inversion strength plays a critical role in evolution of cloud thickness and cov- erage (Wood and Bretherton, 2004). Although GPS RO cannot infer the ABL temperature inversion directly, the RO refractivity gradient depends strongly on both temperature and moisture gradients, and thus can be used as a valuable observational constraint to the $\mathrm{ABL}$ inversion strength and the $\mathrm{ABL}$ top entrainment rate.

\subsection{Typical ABL structure over VOCALS region}

Figure 2a shows a typical ABL temperature and humidity structure from radiosonde observation over the VOCALS region. The ABL top height is well defined by separating a moist, well-mixed boundary layer from a dry free troposphere above. The stratocumulus cloud is trapped underneath the inversion base (at $\sim 1.5 \mathrm{~km}$ ) and is marked by the box with relative humidity (not shown) exceeding $94 \%$ (Wang et al., 1999). A very interesting kink is seen in the radiosonde temperature profile at the cloud base $(\sim 1 \mathrm{~km})$, showing a change in the temperature lapse rate from a nearly dryadiabatic $\left(\sim 9.5^{\circ} \mathrm{C} \mathrm{km}^{-1}\right.$, a well-mixed ABL) to a saturatedadiabatic lapse rate $\left(\sim 4.3^{\circ} \mathrm{C} \mathrm{km}^{-1}\right)$ inside the cloud. The near-coincident ECMWF analysis profile (Fig. 2b) shows a lower inversion base (i.e., cloud top height) at $\sim 1.1 \mathrm{~km}$ with a smoother transition across the ABL top in temperature and specific humidity. The reduced sharpness is likely due to the coarser vertical resolution in ECMWF analysis $(\sim 200$ $\mathrm{m}$ vertical sampling). As expected, the small structures of the transition from dry-adiabatic to saturated-adiabatic in the radiosonde are not present in the ECMWF profile.

Based on the atmospheric temperature, humidity and pressure of the radiosonde and ECMWF data, the refractivity can be derived (Smith and Weintraub, 1953) and directly compared with COSMIC RO observations. It is important to note that the opposite changes in temperature and moisture across the ABL top lead to an enhanced decrease in refractivity (Fig. 2c). Both the ECMWF and COSMIC refractivity profiles agree well with the radiosonde above the inversion base $(\sim 1.5 \mathrm{~km})$. Below this level, the ECMWF profile shows a much reduced gradient across the ABL top, yet, matches well with the radiosonde below $\sim 1.1 \mathrm{~km}$. COSMIC refractivity profile, on the other hand, shows systematically negative errors inside the ABL.

Assuming a local spherically symmetric (or horizontally homogeneous) atmosphere, one can compute the bending angle profile (Fig. 2d) as would be observed by GPS RO from a radiosonde or ECMWF refractivity profile (see details in Sect. 4.3). The maximum bending angle generally corresponds to the MRG. As seen in Fig. $2 \mathrm{c}$ and d, the sharp refractivity gradient at the ABL top in the radiosonde $(\sim 1.5 \mathrm{~km})$ is mapped into a sharp increase in bending angle at $\sim 3 \mathrm{~km}$ (in impact height, i.e., the impact parameter minus the Earth's radius). The high-resolution COSMIC RO bending (5-m smoothed) captures the transition height with a large bending increase very well. The standard RO bending (with the $\sim 200-\mathrm{m}$ vertical smoothing) also shows a large 
(a)

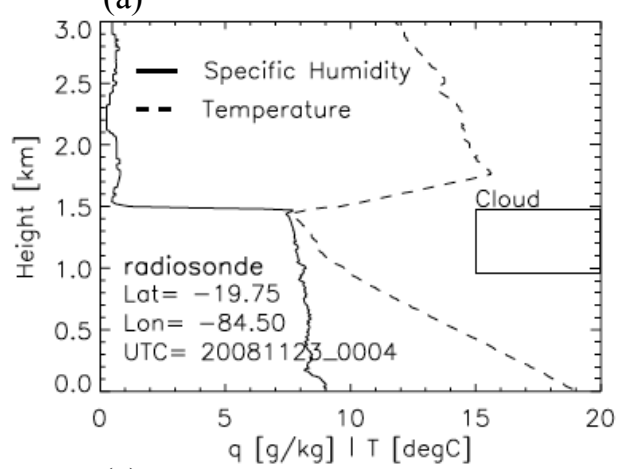

(c)

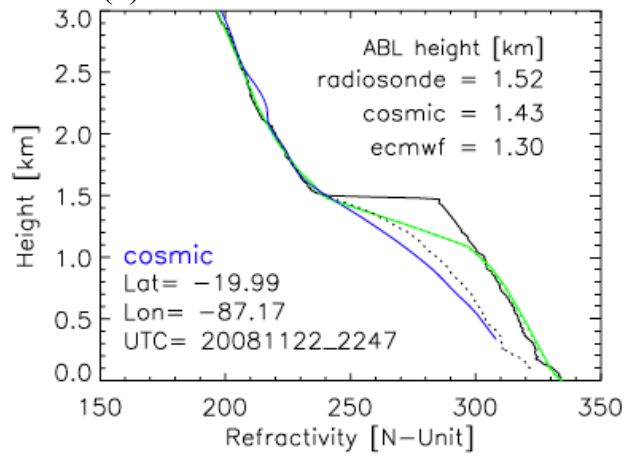

(b)

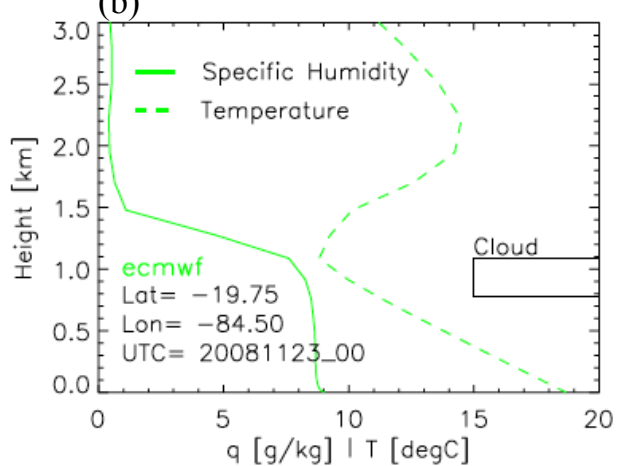

(d)

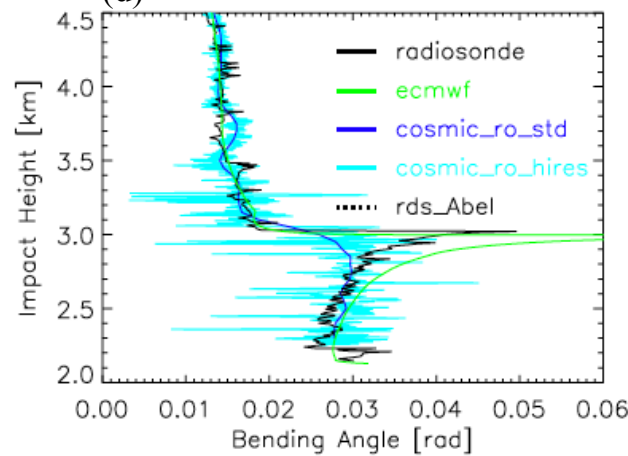

Fig. 2. Typical ABL structure in one VOCALS radiosonde (black) with the near-coincident COSMIC-RO (blue) and ECMWF analysis (green) profiles. (a) Radiosonde specific humidity and temperature; (b) ECMWF analysis specific humidity and temperature; The boxes in (a, b) indicate the cloud region with relative humidity exceeding 94\%; (c) refractivity of radiosonde (black), COSMIC RO (blue) and ECMWF analysis (green) as well as simulated refractivity retrieval (black-dotted) based on the simulated radiosonde bending; the ABL heights are listed in the upper right corner, respectively; (d) simulated bending angle of radiosonde (black), ECMWF analysis (green) as well as the standard (blue-solid) and high-resolution (cyan) COSMIC RO bending angles.

increase across the ABL top but reveals a smaller and lower peak bending, which results in a slightly lower MRG height $(\sim 1.43 \mathrm{~km})$. Although the ECMWF profile produces a much weaker ducting layer at a lower MRG height $(\sim 1.3 \mathrm{~km})$, the impact height of the peak bending in this ECMWF profile is close to the radiosonde. Nevertheless, the bending below the peak is systematically larger than the radiosonde.

Several studies have utilized such features in RO refractivity profile for detecting the ABL height by locating the height of maximum refractivity gradient (MRG) in GPS RO profiles with some differences in algorithm implementation (e.g., Sokolovskiy et al., 2006; Ao et al., 2008; Basha and Ratnam, 2009; Guo et al., 2011; Ao et al., 2012). For a well-defined ABL (e.g., over VOCALS region), the refractivity gradient method is consistent with other conventional definitions (e.g., gradient method based on temperature or humidity profiles) (Basha and Ratnam, 2009; Seidel et al., 2010; von Engeln and Teixeira, 2011; Ao et al., 2012). However, over the region without a well-defined ABL transition layer (e.g. the deep convection zone), the MRG method could result in significant discrepancies in ABL height comparing with other definitions (e.g., von Engeln and Teixeira, 2011). In this paper, we choose the MRG method and define the
ABL height as the altitude where the refractivity gradient reaches its most negative value anywhere below $5 \mathrm{~km}$. As the elevated ABL height is the main focus of this study, the lowest 50-m a.m.s.l. are excluded. This is because some strong moisture gradients found near the warm ocean surface in ECMWF analysis could significantly lower the ABL heights derived from the MRG method (von Engeln and Teixeira, 2011). Note that the three datasets are associated with different vertical resolution: radiosonde $(10-\mathrm{m}), \mathrm{RO}(\sim 200-$ $\mathrm{m}$ ) and ECMWF (varying from $40-\mathrm{m}$ to $200-\mathrm{m}$ ). To ensure the same ABL height quality derived with the MRG method, we interpolate RO and ECMWF refractivity profiles (cubic-spline) on a 10-m vertical grid before the gradient calculation. RO shows a reasonably good agreement with radiosonde in ABL height with a small negative error of $\sim 90-\mathrm{m}$, while ECMWF analysis has a larger negative error of $\sim 200$-m (Fig. 2c).

Given the simulated radiosonde bending angle profile in Fig. 2d, the radiosonde refractivity profile expected from RO observation can be derived (dotted-line in Fig. 2c) following the standard Abel-inversion integration (e.g., Fjeldbo et al., 1971; Kursinski et al., 1997). The simulated refractivity profile also shows negative errors against the original radiosonde 

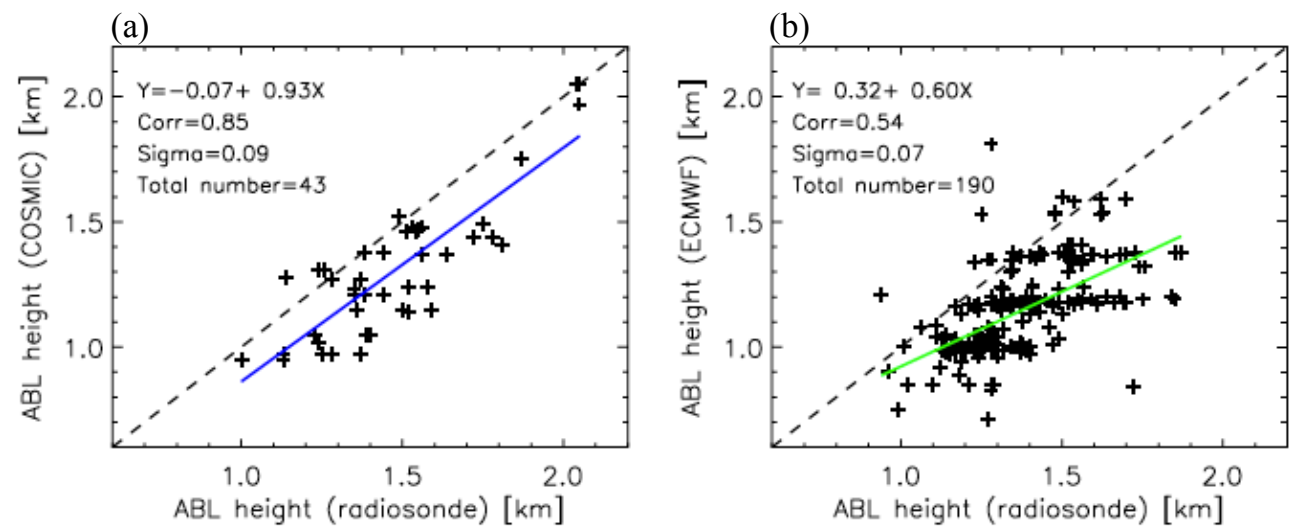

Fig. 3. (a) Scatter-plot of the ABL heights for near-coincident radiosonde (100-m smoothing) and COSMIC RO soundings with the linear fit (blue); (b) scatter-plot of the ABL heights for near-coincident radiosonde and ECMWF with the linear fit (green).

profile. Such negative errors are solely caused by the socall ducting phenomenon (i.e., refractivity gradient exceeds the critical refraction, $-157 \mathrm{~N}$-unit $\mathrm{km}^{-1}$ ) at the top of the ABL where the Abel-inversion integration becomes a nonunique problem (Sokolovskiy, 2003; Ao et al., 2003; Xie, et al., 2006; Xie et al., 2010a). In this example, the COSMIC refractivity closely matches the simulated Abel-retrieved radiosonde refractivity profile, which strongly suggests the negative errors in COSMIC refractivity are primarily caused by the ducting. Additional negative errors in the RO refractivity profile, relative to the radiosonde Abel profile, could be attributed to other factors such as the space and time difference between the RO and the radiosonde $(\sim 268 \mathrm{~km}, \sim 1 \mathrm{~h})$ and the representativeness difference between the point measurement for radiosonde and the limb sounding (horizontally averaged) observation for GPS RO.

\subsection{ABL height comparisons}

Out of a total of 190 radiosonde profiles from the VOCALS field campaign $\left(15-25^{\circ} \mathrm{S}, 70-86^{\circ} \mathrm{W}\right)$, only 25 were found to be near-coincident with the quality-screened COSMIC RO profiles within $3 \mathrm{~h}$ in time and $300 \mathrm{~km}$ in space. Further searching over the radiosondes (142 profiles) from cruises in October of 2006 and 2007, another 18 near-coincident pairs were found. Figure 3 a compares the ABL heights for the 43 matched cases (mean time difference $\sim 1.5 \mathrm{~h}$; mean-distance $\sim 226 \mathrm{~km})$, and a low bias $(\sim 100-\mathrm{m})$ is evident in the RO measurements. Linear regression analysis shows a high correlation coefficient $(\sim 0.85)$ with small 1 -sigma uncertainty $(\sim 90 \mathrm{~m})$. The limited number of near-coincident cases and the relatively large space/time difference between RO and the radiosondes could contribute to the ABL height difference. The radiosonde-ECMWF (190 pairs) comparison, as shown in Fig. 3b, yields a low bias in the ECMWF analysis. The correlation is lower $(\sim 0.54)$ and the 1-sigma uncertainty is $\sim 70 \mathrm{~m}$. The systematic low bias in ECMWF ABL height is consistent with previous weather and climate model studies over the region (e.g., Bretherton et al., 2004; Rahn and Garreaud, 2010; Wyant et al., 2010; von Engeln and Teixeira, 2011; Wang et al., 2011).

\section{Atmospheric boundary layer over southeast Pacific Ocean}

The short-period VOCALS campaign and the relatively sparse sampling of COSMIC RO soundings greatly limit the number of near-coincident pairs. COSMIC RO has a random sampling pattern especially in the zonal direction (see details in Sect. 5), whereas radiosondes and ECMWF analysis have relatively uniform and dense sampling over the campaign area. An alternative approach is to evaluate ABL parameters through their PDF (probability density function or histogram) using all available data sets over the region of interest. These PDFs can also yield differences among COSMIC RO, radiosondes and ECMWF analysis.

\subsection{ABL height comparisons}

In this comparison the ABL heights are first derived from the refractivity profiles using the MRG method, and then sorted into 100-m bins between the surface and $4 \mathrm{~km}$. The PDF is derived in each bin, normalized by the bin size and the total number of samples within $0-4 \mathrm{~km}$ height range. The PDF of the ABL heights for the 25 radiosondes (100-m smoothing) and the near-coincident COSMIC soundings as well as the ECMWF analysis are shown in Fig. 4a. The PDF of the COSMIC shows a better agreement with the radiosonde than the ECMWF. Both the RO and the radiosonde show a maximum frequency of the ABL heights at $\sim 1.5 \mathrm{~km}$ and exhibit a similar distribution. The ECMWF analysis, however, shows a lower ABL height at its peak frequency $(\sim 1.1 \mathrm{~km})$, with the PDF shifting to the lower heights. 
(a)

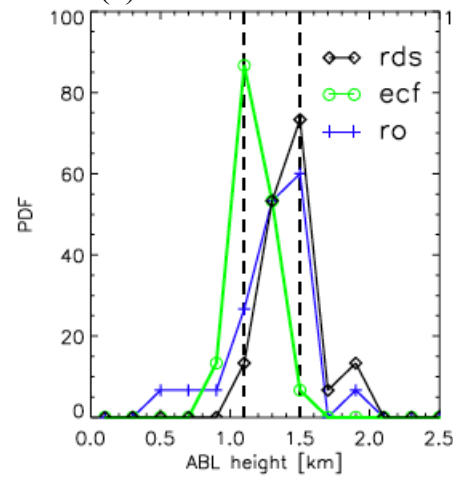

(b)

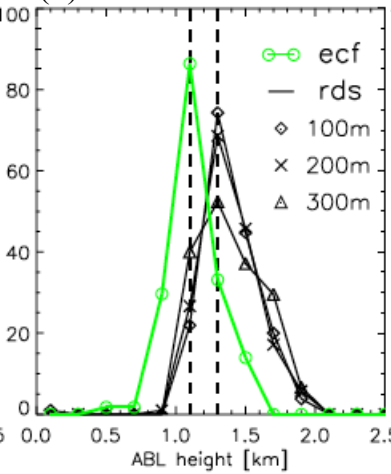

(c)

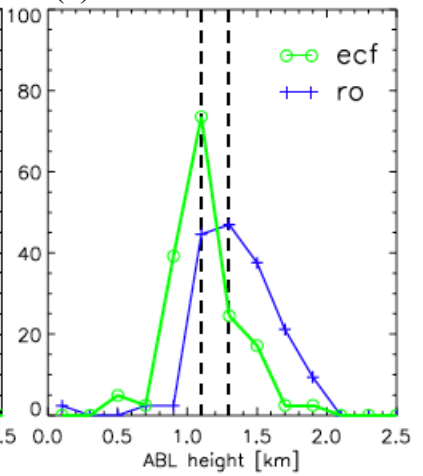

Fig. 4. The PDF of the ABL heights (a) for radiosondes (25 profiles, with 100-m smoothing) and the near-coincident COSMIC RO and ECMWF analysis; (b) for radiosonde (190 profiles) with three vertical smoothing intervals (100, 200 and $300 \mathrm{~m})$ and the near-coincident ECMWF analysis over the region ( $15-25^{\circ} \mathrm{S}, 70-86^{\circ} \mathrm{W}$ ) from 25 October to 1 December 2008; (c) for COSMIC RO soundings (70 profiles) and the near-coincident ECMWF analysis over the region $\left(20-25^{\circ} \mathrm{S}, 70-86^{\circ} \mathrm{W}\right)$ from 25 October to 1 December 2008 . For better illustration, the normalized PDF is divided by 3 to scale the maximum PDF close to 100. The shape of the PDF is not changed due to the scaling.

A reduced vertical resolution results in a decrease in the vertical refractivity gradient and thus affects the ABL height derived from the MRG method. Figure $4 \mathrm{~b}$ shows the PDF of the ABL heights for the 190 radiosondes (within $15-25^{\circ} \mathrm{S}$ ) after applying three vertical smoothing levels (100, 200 and $300 \mathrm{~m})$. The ABL height at peak frequency $(\sim 1.3 \mathrm{~km})$ does not change due to different levels of smoothing. The $200-\mathrm{m}$ smoothing result is almost identical to the 100-m smoothing. While the 300-m smoothing does reduce the peak frequency of $\mathrm{ABL}$ height at $1.3 \mathrm{~km}$, but the overall shape (e.g., the width) of the PDF is maintained. This is because the ABL top height is very well-defined, marked by one dominant sharp gradient in the lower troposphere, and is less sensitive to the smoothing. All three curves show the majority of ABL heights varying from $0.8 \mathrm{~km}$ to $2.1 \mathrm{~km}$. On the other hand, the near-coincident ECMWF profiles (190 pairs, mean time difference $=1.5 \mathrm{~h}$; mean distance $=85 \mathrm{~km}$ ) show a systematically lower ABL height $(1.1 \mathrm{~km})$ at the peak occurrence frequency comparing to the radiosondes (Fig. 4b). This low bias ( 200-m) in the ECMWF ABL height is consistent with the scatter plot in Fig. 3b.

We also compute the PDF of ABL heights from COSMIC soundings over the region $\left(20-25^{\circ} \mathrm{S}, 70-86^{\circ} \mathrm{W}\right)$ during the VOCALS campaign period along with the nearcoincident ECMWF analysis (70 pairs, mean time difference $=1.5 \mathrm{~h}$; mean distance $=130 \mathrm{~km}$ ). COSMIC soundings show the peak frequency of ABL height at $1.3 \mathrm{~km}$, while the ECMWF analysis shows systematically lower ABL heights with a peak occurrence frequency at $1.1 \mathrm{~km}$ (Fig. 4c). COSMIC soundings are capable of resolving higher ABL with realistic range of $\mathrm{ABL}$ heights variation $(0.9-2.1 \mathrm{~km})$ as revealed by the radiosondes (Fig. 4b). On the other hand, the ECMWF analysis systematically underestimates the ABL heights and shows limited capability of correctly reproducing the ABL height variations.

\subsection{Maximum refractivity gradient (MRG) at the ABL top}

Sharp temperature inversions and drops in moisture both contribute to the large gradient of refractivity across the ABL top. Note that the inversion strength is an important ABL parameter that measures the stability of the transition layer and controls the moisture and momentum fluxes exchange between the boundary layer and the free troposphere. It also strongly affects the cloud-top entrainment rate and the evolution of stratocumulus clouds below the inversion (Wood and Bretherton, 2004). The refractivity gradient measurement, therefore, is important for understanding the cloud-top entrainment and other ABL processes.

In this section we investigate the PDF of MRG at the ABL height using the near-coincident radiosondes, ECMWF analysis and COSMIC RO as shown in Fig. $4 \mathrm{~b}$ and c. To account for the large range of MRG values, we take the logarithm of the absolute value of MRG to base 10, and calculate the PDF with even bin size of 0.2 from 0 to 3 . These bins are later converted back to the corresponding MRG from -1 to -1000 (N-unit $\mathrm{km}^{-1}$ ) in linear scale. Again, the PDF that measures the number of occurrences in each bin is normalized by the bin size and the total number of samples.

As expected, the refractivity gradient at the ABL top, or the MRG value, depends on the vertical resolution of the measurements. Lower vertical resolution leads to a smaller gradient. When the MRG is larger (more negative) than the critical refraction $\left(-157 \mathrm{~N}\right.$-unit $\left.\mathrm{km}^{-1}\right)$ the ducting condition occurs. With the original 10-m sampling, the MRG values of the radiosondes (190 profiles) vary from -200 to -1000 ( $\mathrm{N}$-unit $\mathrm{km}^{-1}$ ). To investigate the smoothing effect on the MRG, we apply different smoothing lengths on the radiosonde data. Figure 5a shows the PDF of MRG for the radiosondes and the near-coincident ECMWF. The PDF peak 
(a)

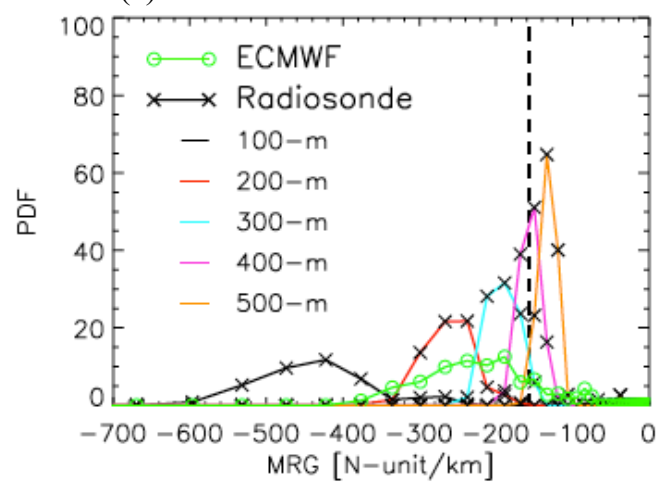

(b)

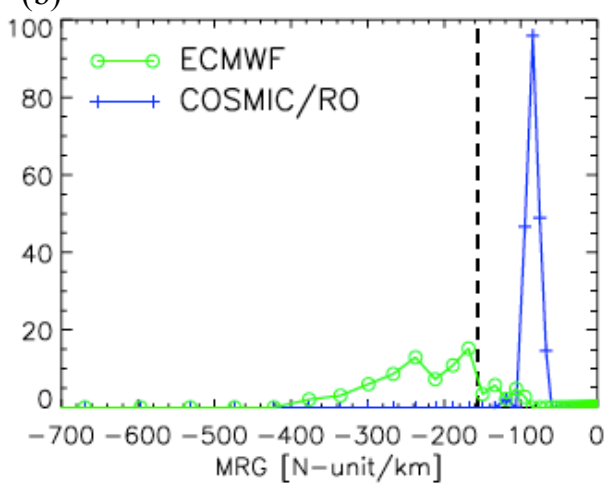

Fig. 5. (a) PDF of MRG for the radiosondes (190 profiles, with different vertical smoothing) and the near-coincident ECMWF analysis over the region $\left(15-25^{\circ} \mathrm{S}, 70-86^{\circ} \mathrm{W}\right)$; (b) PDF of the MRG for COSMIC RO soundings (70 profiles) and the near-coincident ECMWF analysis over the region $\left(20-25^{\circ} \mathrm{S}, 70-86^{\circ} \mathrm{W}\right)$ from 25 October to 1 December 2008 . The vertical black dashed lines denote the critical refraction gradient $\left(-157 \mathrm{~N}\right.$-unit $\left.\mathrm{km}^{-1}\right)$. The normalized PDF is multiplied by 20 for better illustration.

shifts to a smaller MRG value when the smoothing length applied on the radiosondes increases. After the 100-m or 200-m vertical smoothing, the radiosondes still show $\sim 100 \%$ ducting (i.e., the MRG exceeds critical refraction as indicated by the vertical dashed-line). The $100-\mathrm{m}$ smoothing shows the peak PDF at $-420\left(\mathrm{~N}\right.$-unit $\left.\mathrm{km}^{-1}\right)$, a very steep gradient that is rarely produced in the ECMWF analysis. At the 500-m smoothing, most radiosonde profiles are deprived of ducting layer.

On the other hand, the near-coincident ECMWF analysis (with $\sim 200$-m vertical sampling) shows a much broader range of MRG variations (from -70 to $-400 \mathrm{~N}$-unit km $\mathrm{km}^{-1}$ ) that do not match either PDFs of the radiosondes with 200-m or 300-m smoothing. The MRG of ECMWF reaches around $-200\left(\mathrm{~N}\right.$-unit $\left.\mathrm{km}^{-1}\right)$ at peak frequency, which is close to the radiosondes with 300-m smoothing. But it also shows much higher frequency of stronger gradient $(<-240 \mathrm{~N}-$ unit $\mathrm{km}^{-1}$ ) as compared with the 300 -m smoothed radiosondes. The large discrepancy between the near-coincident ECMWF analysis and the radiosonde with various verticalsmoothing levels could not be simply explained by the limited vertical resolution in the ECMWF model. Instead, it could imply some deficiency in the model physics to reproduce the correct distribution of the MRG at the ABL top.

Similarly, the PDF of the MRG for COSMIC soundings over region $\left(20-25^{\circ} \mathrm{S}, 70-86^{\circ} \mathrm{W}\right)$ is plotted against the nearcoincident ECMWF analysis (Fig. 5b). The ECMWF analysis shows a similar PDF in Fig. 5a, but with a slightly higher frequency for lower MRG, which could be related to weaker inversions at higher latitudes towards the south. On the other hand, the RO measurements significantly underestimate the MRG. The MRG tends to saturate at $\sim-110\left(\mathrm{~N}\right.$-unit km $\left.{ }^{-1}\right)$, which is much smaller than the critical refraction $(-157 \mathrm{~N}$ unit $\mathrm{km}^{-1}$ ).
The radiosondes confirm the prevalence of ducting conditions at the ABL top over the VOCALS region. In the presence of ducting, the standard RO refractivity retrieval becomes a non-unique inversion problem (Sokolovskiy, 2003; Xie et al., 2006). With the assumption of 1-D atmosphere with horizontally extended ducting layer at the ABL top, the standard RO refractivity retrieval will have a MRG value exactly equal to the critical refraction, no matter how much the MRG exceeds the critical refraction in the real atmosphere.

The delta function like PDF in the MRG of COSMIC (Fig. 5b) implies the dominant presence of ducting, which leads to the convergence of the MRG (saturated) to the critical refraction threshold in RO soundings. However, the weaker refractivity gradients (e.g., $-110 \mathrm{~N}$-unit $\mathrm{km}^{-1}$ ) than the critical refraction $\left(-157 \mathrm{~N}\right.$-unit km$\left.{ }^{-1}\right)$ in COSMIC RO soundings is partially due to the vertical smoothing ( $\sim 200$ $\mathrm{m})$ applied in the standard retrieval process. Moreover, the horizontal inhomogeneity in the atmosphere can also introduce extra smoothing effects (e.g., Ao, 2007) but requires further investigation. Overall, the systemically smaller MRG in COSMIC soundings should be primarily caused by ducting but not by the lack of vertical resolution.

\subsection{Refractivity bias ( $N$-bias) due to ducting in RO soundings}

The VOCALS radiosondes and ECMWF analysis confirm a wide-spread ducting layer at the top of the ABL over the SE Pacific (Fig. 5). The ducting layer has a profound impact on the propagation of radio waves and could result in systematically negative biases (or called $\mathrm{N}$-bias) in RO refractivity retrievals (Sokolovskiy, 2003; Ao et al., 2003; Xie et al., 2006), which result from the non-unique Abel inversion problem with details described in Xie et al. (2006). Xie et al. (2010a) reveal large $N$-biases in GPS RO soundings over subtropical eastern oceans across the globe, including the SE 
Pacific. The regions with significant $N$-biases are highly correlated with the area where elevated ducting prevails (von Engeln and Teixeira, 2004; Lopez, 2009).

Here we investigate the PDF of the maximum $N$-bias caused by the ducting through simple geometric-optics (GO) simulations. Based on the VOCALS radiosonde and ECMWF refractivity profiles, we conducted a simple twostep GO simulation: (1) a forward operator to simulate the GPS RO bending angle measurement by integrating an input refractivity profile, which represents a one-dimensional atmosphere; and (2) an inverse operator to simulate the GPS $\mathrm{RO}$ refractivity retrieval process by integrating the bending angle profile (from the first step) through the standard Abel integration. The two GO operators that are specifically built for simulating ducting cases are fully described in Xie et al. (2006). In the absence of ducting, the Abel-retrieved refractivity profile will be identical to the input refractivity profile and introduce no bias. However, in the presence of ducting, the Abel-retrieved refractivity profile becomes negatively biased inside the ABL. The solely ducting-induced $N$-bias (in percentile $)$ is defined as $\left(N_{\text {_retrieval }}-N_{\text {_input }}\right) / N_{\text {input }} \times 100$. The maximum $N$-bias of each simulated profile is generally near the top of the ducting layer, i.e. the ABL top. Such simulations are applied on all VOCALS radiosondes and the near-coincident ECMWF profiles. We then bin the $N$-biases from $-20 \%$ to 0 with a $2 \%$ interval. The PDF of the $N$-bias is then normalized by the bin size and the total number of samples.

As shown in Xie (2006), the maximum $N$-bias introduced by the ducting is linearly proportional to the refractivity gradient at the ABL top and thus is vertical resolution dependent. In the above GO simulations, we compute the $N$-bias from the radiosonde data with various vertical-smoothing intervals. Figure 6 shows the PDF of $N$-bias for radiosonde and ECMWF data. Consistent with the results in Fig. 5a, the radiosonde profiles with the 100-m and 200-m smoothing preserve the ducting and the peak frequency of maximum $N$-bias is as large as $-12 \%$ and $-8 \%$, respectively. With further smoothing, the $N$-bias reduces due to a weaker MRG in the ducting layer. At the 500-m smoothing, most profiles show zero bias, since the MRG rarely exceeds critical refraction at this level of smoothing. On the other hand, the PDF of the ducting-induced $N$-bias in the ECMWF is most consistent with the radiosonde result at the 300-m smoothing, but shows a broader spread.

\section{Seasonal mean ABL height climatology and the transect along $\sim 20^{\circ} \mathrm{S}$}

It has been shown above that COSMIC RO is capable of detecting the $\mathrm{ABL}$ top height from the sharp refractivity gradient despite the $N$-bias of RO profiles inside the ABL due to ducting. We further generate a seasonal mean ABL height climatology using the aforementioned MRG method for

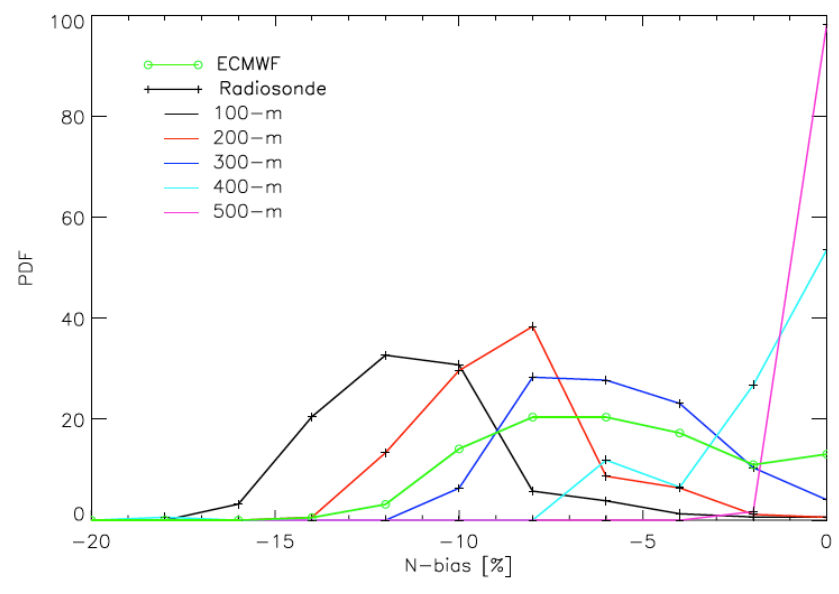

Fig. 6. PDF of the maximum $N$-bias due to ducting for radiosondes (190 profiles, with different vertical smoothing) and the nearcoincident ECMWF analysis over the region $\left(15-25^{\circ} \mathrm{S}, 70-86^{\circ} \mathrm{W}\right)$. The normalized PDF is multiplied by 2 to scale the maximum PDF close to 100 .

COSMIC RO soundings over the SE Pacific $\left(0-50^{\circ} \mathrm{S}, 70-\right.$ $140^{\circ} \mathrm{W}$ ) during the boreal fall season (September-November in 2007, 2008 and 2009). The same method is also applied to ECMWF analysis (down-sampled to $1^{\circ}$ latitude $\times 1^{\circ}$ longitude) profiles in the region. The ABL heights and the MRG along the $\sim 20^{\circ} \mathrm{S}$ transect for the VOCALS radiosondes (200-m vertical smoothing), COSMIC (centered at $\sim 22.5^{\circ} \mathrm{S}$ with 5-deg gridded-average) and ECMWF analysis (at $22^{\circ} \mathrm{S}$ grid) are also analyzed.

\subsection{ABL height climatology}

Deepening of the ABL westward off the coast is clearly evident in both COSMIC RO and ECMWF data (Fig. 7a, b). COSMIC RO shows an overall deeper ABL and a significant different pattern as compared to the ECMWF. A dipole feature in ABL heights is seen in COSMIC RO, i.e., a minimum ABL height $(\sim 1.2 \mathrm{~km})$ centered at $\left(20^{\circ} \mathrm{S}, 75^{\circ} \mathrm{W}\right)$ just off the coast of Peru and Chile border; and a maximum ABL height $(\sim 2.3 \mathrm{~km})$ centered at $\left(15^{\circ} \mathrm{S}, 135^{\circ} \mathrm{W}\right)$. The $\mathrm{ABL}$ heights gradually increase westward (to warmer sea-surfacetemperature, SST) from a near-coast minimum at $\sim 75^{\circ} \mathrm{W}$ to a maximum at $\sim 135^{\circ} \mathrm{W}$ within $\sim 8-25^{\circ} \mathrm{S}$. A "tongue" of low ABL heights extends northwestward from the local minimum and introduces meridional variations in ABL heights near the coast. Offshore at higher latitudes (e.g., beyond $\sim 25^{\circ} \mathrm{S}$ and westward of $\sim 90^{\circ} \mathrm{W}$ ), the ABL heights become rather homogeneous in zonal direction while present large meridional gradient (e.g., shallower at higher latitudes), which is consistent with the SST pattern (no shown).

The ECMWF analysis also captures the general feature of the deepening ABL westward but shows systematically shallower ABL (Fig. 7b). A similar dipole feature is also present but at different locations, i.e., a minimum $(\sim 0.7 \mathrm{~km})$ centered 

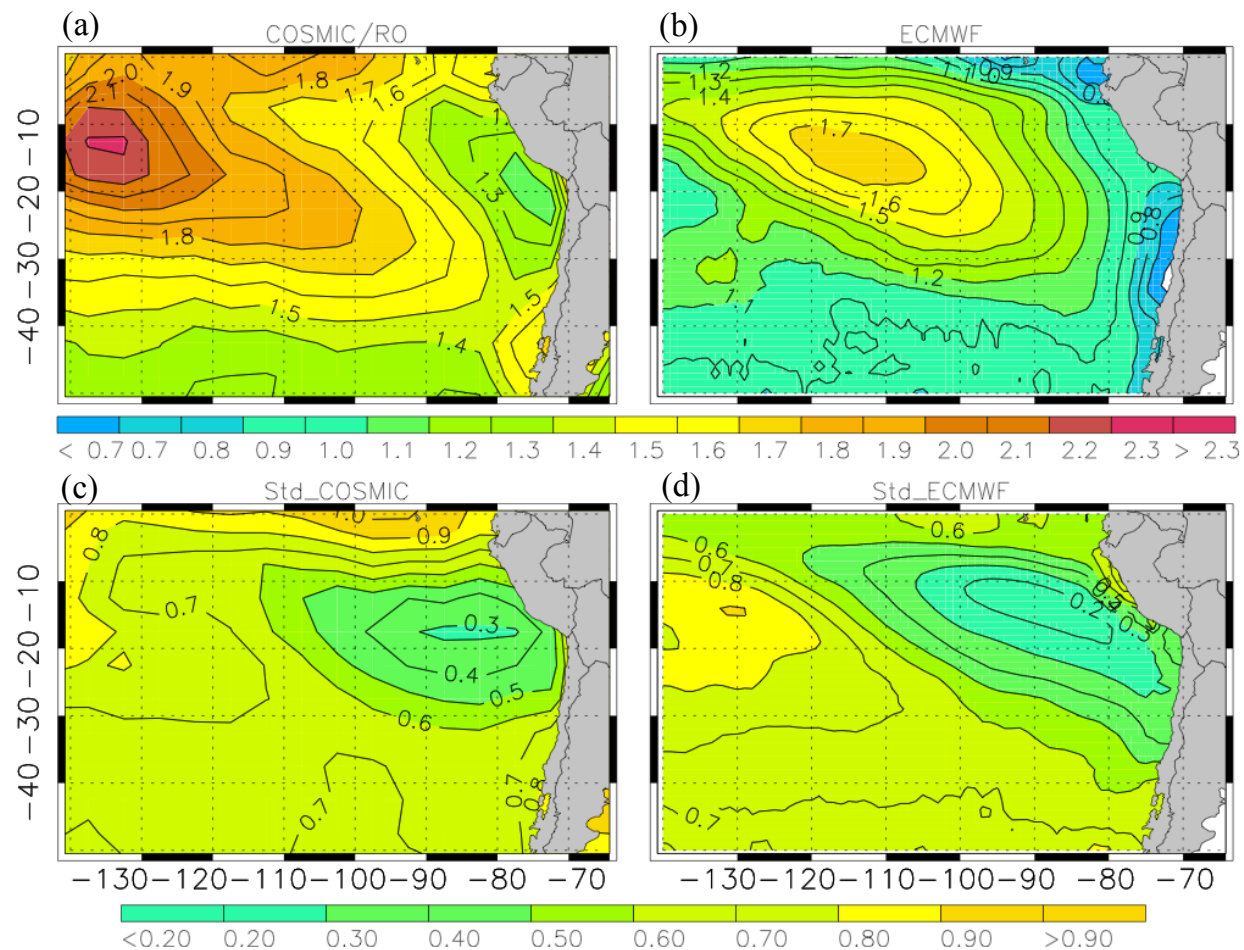

(d)
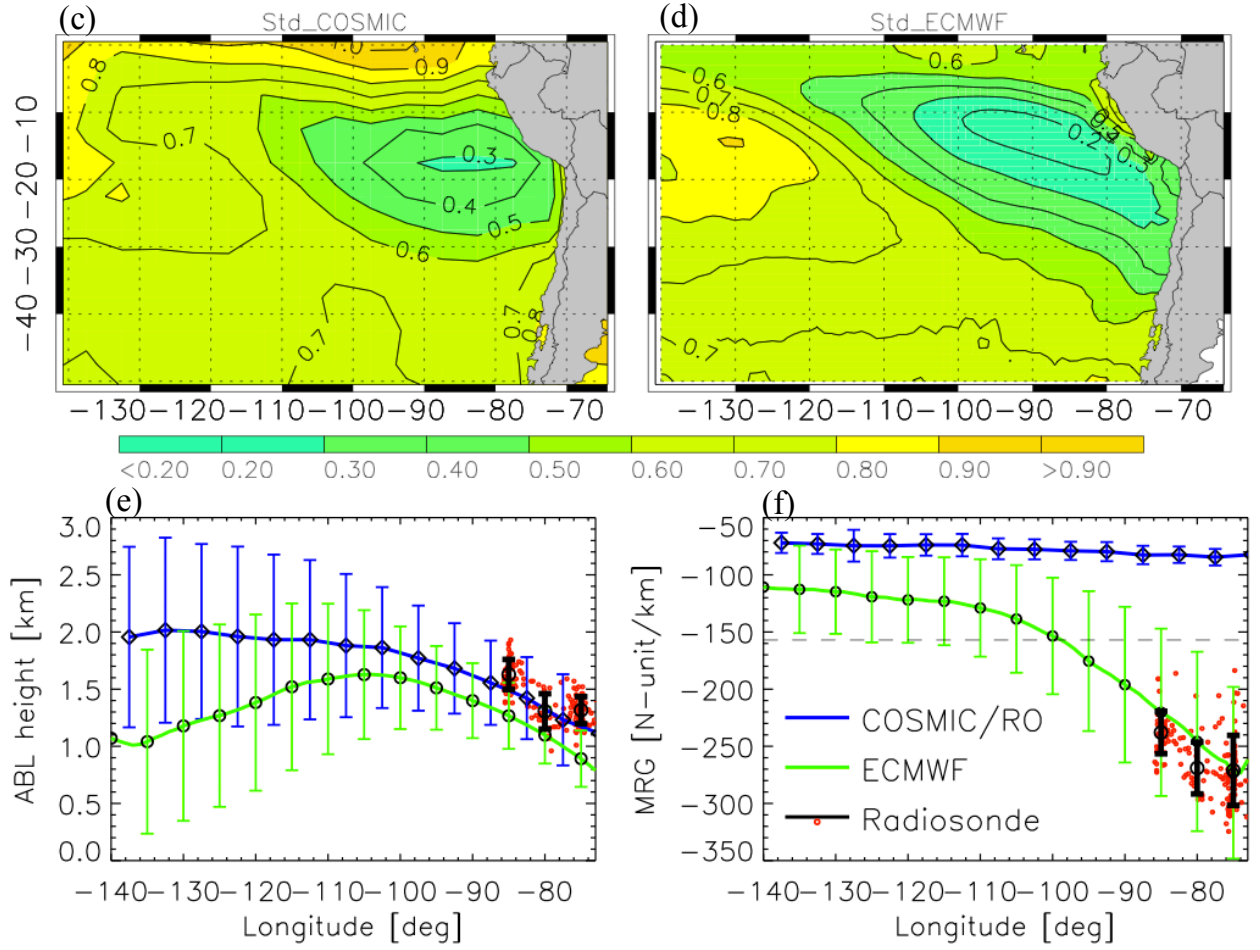

Fig. 7. Mean ABL height climatology (September-November in 2007, 2008 and 2009) for (a) COSMIC RO and (b) ECMWF analysis. The standard deviation of the ABL heights is shown in (c) and (d), respectively. The ABL heights and the MRG (mean and standard deviation) along the transects at: $\sim 22.5^{\circ} \mathrm{S}$ (COSMIC), $22^{\circ} \mathrm{S}$ (ECMWF) and $\sim 20^{\circ} \mathrm{S}$ (radiosonde) are illustrated in (e) and (f) respectively. The horizontal black dashed line in (f) denotes the critical refraction gradient.

at the Chilean coastal region $\left(\sim 30^{\circ} \mathrm{S}, 72^{\circ} \mathrm{W}\right)$ and a maximum $(\sim 1.7 \mathrm{~km})$ centered at $\left(15^{\circ} \mathrm{S}, 115^{\circ} \mathrm{W}\right)$. It is also interesting to note that, ECMWF analysis shows a small meridional variation in $\mathrm{ABL}$ heights between $\sim 8^{\circ} \mathrm{S}$ and $30^{\circ} \mathrm{S}$ near the coast $\left(70-100^{\circ} \mathrm{W}\right)$, but COSMIC RO shows larger meridional gradients.

A similar pattern of the ABL height variations (mean standard deviation) with comparable magnitude is shown in Fig. $7 \mathrm{c}$ and $\mathrm{d}$. The ABL height variations tend to be smaller over the stratocumulus region near the coast with a local minimum of $\sim 300-\mathrm{m}$ at $\left(18^{\circ} \mathrm{S}, 85^{\circ} \mathrm{W}\right)$ in COSMIC and a smaller amplitude $(\sim 200-\mathrm{m})$ slightly northward at $\left(15^{\circ} \mathrm{S}\right.$, $90^{\circ} \mathrm{W}$ ) in ECMWF analysis. The variations increase in both westward and meridional directions. A local maximum in
ECMWF $(\sim 0.8 \mathrm{~km})$ is clearly seen at $\sim 130^{\circ} \mathrm{W}$ within 10 $25^{\circ} \mathrm{S}$, where the trade cumulus are located. COSMIC shows a slightly smaller maximum at the similar location. Note that the trade wind inversion could become decoupled from an underneath well-mixed surface layer (e.g., Lock et al., 2000). Such a decoupling process could result in double or even multiple inversion layers besides the trade wind inversion as observed from Hawaii radiosonde soundings (Cao et al., 2007). These multiple sharp structures result in two-mode or even multiple-mode distribution in the refractivity gradient PDFs, which could introduce larger variations in ABL heights from the MRG method. The large variances in ABL heights are also seen over the weak subsidence regions, i.e., near the equator $\left(0-5^{\circ} S\right)$ and at higher latitudes near the 
storm tracks $\left(40-50^{\circ} \mathrm{S}\right)$. The weak subsidence tends to produce less well-defined ABL and thus results in a broader distribution in refractivity gradient PDFs, which could lead to noisier ABL heights derived from the MRG method.

The MRG method performs the best for ABL height detection when the PDF of the refractivity gradients for each profile has one dominant mode, which is generally the case over the stratocumulus regions. A separate study on the refractivity gradient PDFs from COSMIC and ECMWF over the trade wind, equatorial (e.g. Intertropical Convergence Zone, ITCZ) and high-latitude regions will improve our understanding of these more complicated ABL structures and help interpret the difference in the ABL height climatology between COSMIC and ECMWF. A better and more robust ABL height detection algorithm could also be developed and benefit from such study.

\subsection{The ABL structure along the $\sim 20^{\circ} S$ transect}

The bottom two panels in Fig. 7 illustrate ABL height and the maximum refractivity gradient along the $\sim 20^{\circ} \mathrm{S}$ transect. In COSMIC observation, ABL heights increase steadily along the $\sim 22.5^{\circ} \mathrm{S}$ (averaged over $20-25^{\circ} \mathrm{S}$ with a 5-degree longitude bin) transect from off the coast westward to a maximum at $\sim 130^{\circ} \mathrm{W}$. A relatively steep slope of $\sim 30 \mathrm{~m}$ $(100 \mathrm{~km})^{-1}$ westward is seen from $\sim 74^{\circ} \mathrm{W}$ to $\sim 90^{\circ} \mathrm{W}$, and the slope decreases significantly further westward to be $\sim 10 \mathrm{~m}(100 \mathrm{~km})^{-1}$ between $\sim 100^{\circ} \mathrm{W}$ and $\sim 120^{\circ} \mathrm{W}$ (Fig. 7e). The magnitudes of ABL height variations also gradually increases from a near-coast minimum $(\sim 300-\mathrm{m})$ over the stratocumulus regions to a maximum $(\sim 800$-m) over the trade cumulus regions.

Similarly, the ECMWF analysis also clearly demonstrates the ABL deepening westward along the $22^{\circ} \mathrm{S}$ transect from a near-coast minimum to a local maximum at $\sim 105^{\circ} \mathrm{W}$ (Fig. 7e). An identical slope of $\sim 30 \mathrm{~m}(100 \mathrm{~km})^{-1}$ between $75^{\circ} \mathrm{W}$ and $90^{\circ} \mathrm{W}$ is also seen in the ECMWF analysis, and the slope decreases further westward of $90^{\circ} \mathrm{W}$ before reaching the local maximum. Contrary to the persistent deepening ABL offshore in COSMIC observations, the ECMWF ABL heights decrease further westward of $\sim 105^{\circ} \mathrm{W}$. Nonetheless, the variation of the ABL heights along the transect shows slightly smaller amplitude near the coast ( $\sim 200$-m) but very similar amplitude further west in comparison with COSMIC observations.

The ABL heights of individual VOCALS radiosondes $\left(15-22^{\circ} \mathrm{S}, 70-86^{\circ} \mathrm{W}\right)$ are also shown in Fig. 7e (red dots). The mean and standard deviation of the ABL heights at three 5-degree longitude bins (centered at $74^{\circ} \mathrm{W}, 79^{\circ} \mathrm{W}$ and $84^{\circ} \mathrm{W}$ ) are also plotted, which matches well with COSMIC observations at $\sim 79^{\circ} \mathrm{W}$, but slightly higher by $\sim 140 \mathrm{~m}$ at $74^{\circ} \mathrm{W}$ and $84^{\circ} \mathrm{W}$. The VOCALS radiosondes also show the deepening of ABL from $\sim 1.3 \mathrm{~km}$ (median value) at 74 $80^{\circ} \mathrm{W}$ to $\sim 1.6 \mathrm{~km}$ at $\sim 84^{\circ} \mathrm{W}$ along the $20^{\circ} \mathrm{S}$ transect. Such radiosonde $\mathrm{ABL}$ heights derived from MRG method are con- sistent with the ABL heights derived from the radiosonde inversion base from the same region (e.g., Fig. 4a of Rahn and Garreaud, 2010 and Fig. 10 of Wyant et al., 2010) as well as the cloud top height measurements from the airplane cloud radar during the VOCALS campaign (e.g., Fig. 2 in Bretherton et al., 2010).

Figure $7 \mathrm{f}$ shows the maximum refractivity gradient at the ABL top along the $\sim 20^{\circ} \mathrm{S}$ transect. Note that the MRG is vertical resolution dependent. To match the apparent vertical sampling of $\sim 200-\mathrm{m}$ in ECMWF analysis within $\sim 1-2 \mathrm{~km}$, the VOCALS radiosonde profiles are vertically smoothed with a 200-m window. ECMWF shows a maximum MRG near coast $\left(-270 \mathrm{~N}\right.$-unit $\left.\mathrm{km}^{-1}\right)$ and drastically decreasing westward to around $-110\left(\mathrm{~N}\right.$-unit $\left.\mathrm{km}^{-1}\right)$ at $\sim 140^{\circ} \mathrm{W}$. The variations of MRG also decrease significantly further offshore. The radiosonde soundings also show very similar decrease in MRGoffshore but with slightly larger gradients. It is important to note that ECMWF analysis shows dominant ducting presence (MRG $<-157 \mathrm{~N}$-unit $\mathrm{km}^{-1}$ ) from near coast to $\sim 100^{\circ} \mathrm{W}$. VOCALS radiosondes also confirm the prevailing sharp refractivity gradient. On the other hand, the COSMIC RO shows systematically smaller MRG overall, with a seasonal mean maximum $\left(\sim-85 \mathrm{~N}\right.$-unit $\left.\mathrm{km}^{-1}\right)$ near the coast and slightly decreasing to $\sim-70\left(\mathrm{~N}-\mathrm{unit} \mathrm{km}^{-1}\right)$ at $135^{\circ} \mathrm{W}$. Again, the MRG bias in COMIC RO can be largely attributed to the refractivity retrieval bias due to ducting as elaborated in Sect. 4.3.

\subsection{COSMIC RO sampling}

The six-satellite COSMIC constellation is in six inclined orbits with $30^{\circ}$ orbit plane separation, which allow full 24-h local time sampling within one-month at low and mid latitudes (e.g., Pirscher et al., 2010; Xie et al., 2010b). Such diurnal sampling capability is a very appealing feature for compiling the climatology. However, the constellation configuration also leads to meridional sampling differences, i.e., denser sampling per unit area at higher latitudes. It is important to understand the sampling errors in the ABL height climatology due to the inhomogeneous sampling of COSMIC RO in the meridional direction. As shown in Fig. 8a (shaded), during the total of 9-month study period, the sampling is rather homogeneous in the zonal direction. The number of sampling within each $500 \mathrm{~km} \times 500 \mathrm{~km}$ area is $\sim 160$ profiles at $40^{\circ} \mathrm{S}$ and gradually reduces to a minimum of $\sim 50$ profiles at $10^{\circ} \mathrm{S}$ equatorward. Moreover, not all the RO profiles penetrate below 500-m a.m.s.l. The percentage of RO penetrating into the lowest $500-\mathrm{m}$ tends to be lower in the tropics than at higher latitudes (contours in Fig. 8a). For example, only about $20-30 \%$ RO profiles penetrate deep into the lowest $500-\mathrm{m}$ a.m.s.l. near the equator $\left(0-10^{\circ} \mathrm{S}\right)$, whereas the penetration rate increases at higher latitude and reaches over $60 \%$ at $\sim 50^{\circ} \mathrm{S}$. Note that the penetration rate is rather homogeneous in the zonal direction except a slight reduction 

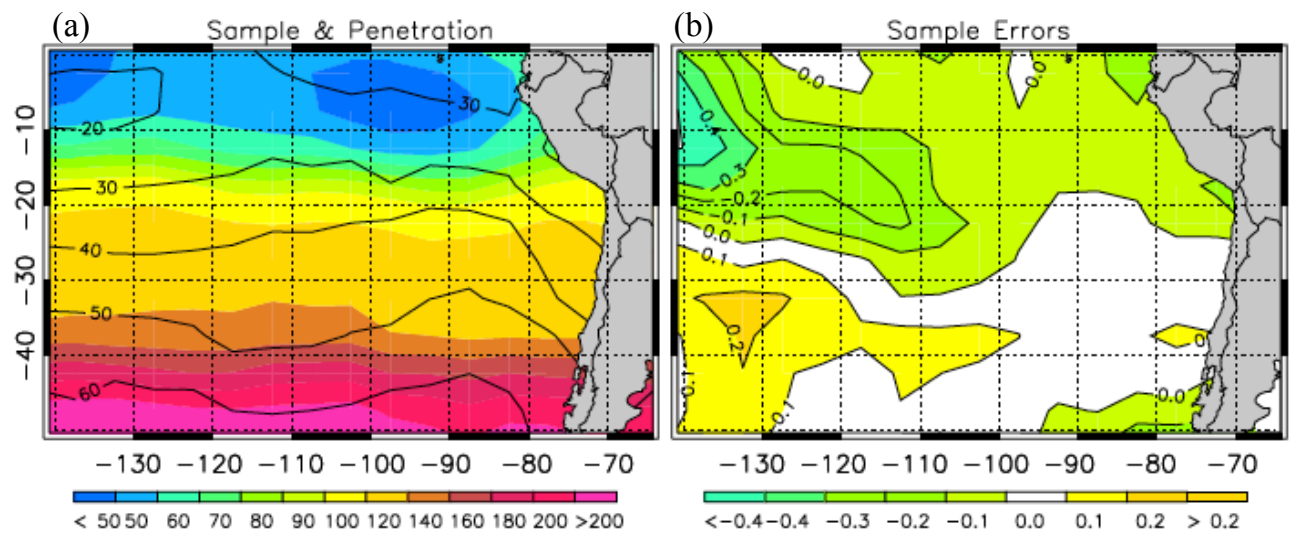

Fig. 8. (a) Number of COSMIC RO soundings per area of $500 \mathrm{~km} \times 500 \mathrm{~km}$ (shaded); the over-plotted contours denote the percentage of soundings that penetrate below 500-m above the m.s.l.; (b) errors in ABL heights caused by the limited COSMIC RO sampling derived from ECMWF analysis (contours, with $0.1 \mathrm{~km}$ interval).

near the coast, where the strongest ducting or temperature inversions are located (i.e., within $15-40^{\circ} \mathrm{S}, 70-85^{\circ} \mathrm{W}$ ).

To estimate potential sampling errors with COSMIC RO, we sample the ECMWF analysis at the RO sounding locations for the study period and create a sub-sampled ABL height climatology (not shown). The difference between the full and sub-sampled ABL height climatology reveals the sampling errors (Fig. 8b). The sampling errors are generally less than 100-m and only become larger at two locations, i.e., negative errors in ABL heights up to $-400-\mathrm{m}$ close to $\left(10^{\circ} \mathrm{S}\right.$, $\left.140^{\circ} \mathrm{W}\right)$, and smaller positive errors of $\sim 200-\mathrm{m}$ near $\left(35^{\circ} \mathrm{S}\right.$, $\left.130^{\circ} \mathrm{W}\right)$. Overall, the limited COSMIC RO sampling results in generally small errors in ABL heights and will not affect the general morphology of the ABL height climatology in Fig. $7 \mathrm{a}$.

\section{Discussions}

Over the SE Pacific, the cool SST along with the large-scale subsidence in the free troposphere lead to a well-defined ABL with a strong temperature inversion and a sharp moisture drop across the ABL top. Such a thin transition layer introduces a very sharp refractivity gradient and thus results in a large bending angle in RO signals, which can be precisely detected by the high-resolution GPS RO soundings. However, there are some limitations in GPS RO for ABL studies, which are discussed in the following.

\subsection{Ducting effect on GPS RO}

The sharp refractivity gradient at the ABL top over the VOCALS region often exceeds the critical refraction threshold (i.e., $-157 \mathrm{~N}$-unit $\mathrm{km}^{-1}$ ) and results in a ducting condition (also referred to as super-refraction). The refractivity gradient is dominated by the moisture gradient in the tropics and subtropics (von Engeln and Teixeira, 2004; Ao, 2007).
At $\sim 1 \mathrm{~km}$ altitude, a mere $-2.5 \times 10^{-2} \mathrm{~g} \mathrm{~kg}^{-1} \mathrm{~m}^{-1}$ in specific humidity will lead to a ducting condition. Nearly all the VOCALS radiosonde profiles (between $15^{\circ} \mathrm{S}$ and $25^{\circ} \mathrm{S}$ ) meet the ducting condition even after the $100-\mathrm{m}$ smoothing. The mean specific humidity gradient at the ABL top of these profiles is as large as $-5.7 \times 10^{-2} \mathrm{~g} \mathrm{~kg}^{-1} \mathrm{~m}^{-1}$ with a standard deviation of $2.8 \times 10^{-2} \mathrm{~g} \mathrm{~kg}^{-1} \mathrm{~m}^{-1}$.

A horizontally extended ducting layer results in a sharp increase in RO bending at the ABL top, which becomes infinitely large (a singularity) in geometric-optics simulation (Sokolovskiy, 2003; Xie et al., 2006). By applying the standard Abel retrieval (i.e., integrating through the infinite bending), the refractivity retrieval based on the spherically symmetric atmosphere assumption produces a maximum refractivity gradient of $-157\left(\mathrm{~N}\right.$-unit $\left.\mathrm{km}^{-1}\right)$ at the top of the ducting layer, where the largest bending occurs. The Abel inversion used for retrieving refractivity becomes a non-unique inversion problem and results in negative refractivity biases below the ducting layer (Xie et al., 2006), as seen in Figs. 2c and 6. The delta-function like PDF of the RO MRG implies the prevalence of ducting. The systematically smaller MRG in $\mathrm{RO}$ refractivity retrieval is primarily caused by the presence of a ducting layer at the ABL top.

\subsection{Impact of horizontal inhomogeneous atmospheric structure on GPS RO}

Over the VOCALS region, the elevated ducting condition is dominant. The idealized 1-D simulation on a horizontally extended ducting layer indicates that the maximum gradients in RO refractivity retrieval should be close to the critical refraction threshold, i.e., $-157 \mathrm{~N}$-unit km ${ }^{-1}$ (e.g., Sokolovskiy, 2003; Xie et al., 2006). The maximum bending angle from current COSMIC RO measurements rarely exceeds 0.05 radians, and so the refractivity gradient rarely exceeds -110 $\left(\mathrm{N}\right.$-unit km${ }^{-1}$ ) over the VOCALS region (Fig. 5b). Horizontal averaging of vertical ABL structures by $\mathrm{RO}$ can 
effectively reduce the observed refractivity gradient (e.g., Ao, 2007). In other words, the radiosonde represents a localized ABL profile, and the ABL height variability may not be uniform over a horizontal span of $\sim 200 \mathrm{~km}$ close to the RO tangent point, where most GPS RO bending along the ray path is accumulated (Kursinski et al., 1997). Figure 7 clearly shows the deepening of the ABL height in both ECMWF and COSMIC RO. The slope in the ABL heights ( $\sim 30 \mathrm{~m}$ per $100 \mathrm{~km}$ at $\sim 20^{\circ} \mathrm{S}$ ) indicates the existence of large-scale horizontal inhomogeneity in the atmosphere. Such smoothing effect would need to be further investigated and quantified. Also the 200-m vertical smoothing applied on RO bending profiles further degrades the vertical resolution when sharp bending angles are present. A more sophisticated filter needs to be developed to preserve the fine structure of the sharp transition in high-resolution bending, which will lead to a larger bending and a sharper refractivity gradient (closer to critical refraction) at the ABL top.

\subsection{Penetration issue and sampling errors}

COSMIC RO receivers adopt the open-loop (OL) tracking technique (Sokolovskiy 2001; Ao et al., 2009), which significantly improves the percentage of RO signals penetratating deep into the lower troposphere. The OL tracking eliminates several problems in previous RO missions (e.g., GPS/MET, CHAMP and GRACE) that use the phase-locked loop (PLL) tracking technique, i.e., early termination of RO signal tracking and systematic tracking errors caused by the complex signal dynamic in the moist lower troposphere (Ao et al., 2003; Beyerle et al., 2003; Anthes et al., 2008). However, the selective lower penetration rate at low latitudes (Fig. 8a) in COSMIC sounding requires further investigation. The improved penetration rate, especially over low latitudes could significantly improve the RO sampling and benefit the science application of GPS RO.

\subsection{COSMIC RO ABL height climatology and its implication to model analysis}

The difference in the monthly mean ABL heights between COSMIC RO and ECMWF analyses (Fig. 7) is substantial and cannot be ignored. Such discrepancy is not caused by the different vertical resolution and the sampling errors in COSMIC RO and could imply the deficiency in model physics. The misrepresentation of MRG and ABL height (Fig. 4) imply incorrect strength and altitude of the inversion layer, which could have profound impact on the entrainment rate and thus cloud evolution simulated in the ECMWF model. The climate models with much coarser vertical and horizontal resolution will have even bigger challenges to correctly represent the two critical ABL parameters.

Due to the lack of ABL observations, the state-of-the-art ABL parameterizations are generally derived and validated by some field campaign observations. The limited spatial and temporal coverage of the measurements could only represent the specific local physical processes under certain synoptic background forcing conditions. The synoptic and meso-scale processes are known to have significant impact on variations of the ABL height or vertical structures (e.g., Toniazzo et al., 2011). Therefore the fine-tuned parameterization scheme developed from such a dataset could potentially be biased to certain atmospheric conditions and limit its general application globally. The global observation of ABL heights from COSMIC RO provides an extremely valuable dataset to evaluate various $A B L$ parameterization schemes through the diagnostic analysis.

Soon after its launch in 2006, COSMIC RO soundings have been operationally assimilated into the leading global weather forecasting centers, such as ECMWF and NCEP. Significant positive impacts of RO observations on the upper troposphere and lower stratosphere have been demonstrated (Cucurull et al., 2006; Healy and Thepaut 2006; Cucurull et al., 2007). However, the much-anticipated positive impact of RO soundings in the lower troposphere, especially over the mid and low latitudes has yet to be demonstrated.

NCEP operationally assimilates COSMIC refractivity profiles. However, the systematic $N$-bias in RO refractivity over the subtropics eastern oceans (Xie et al., 2010a) along with the complicated error characteristics in the lower troposphere results in very limited impact of RO soundings on model analysis.

ECMWF, on the other hand, assimilates RO bending angles, which should not be biased due to ducting. However, in the presence of ducting, $\mathrm{RO}$ bending angle loses information inside the ducting layer and a layer right below, and becomes a singularity (e.g., an infinite bending angle) at the top of the ducting layer (Sokolovskiy, 2003; Xie et al., 2006). Moreover, directly assimilating RO bending angle in the presence of ducting will not avert the non-unique inversion problem, i.e., a single bending angle corresponds to a continuum of refractivity profiles (Xie et al., 2006). For example, given the constraint of the observed $\mathrm{RO}$ bending angle profile, the forward calculation (e.g., computing bending from model refractivity) will not tell the difference among the continuum of model refractivity (or temperature, humidity) profiles with or without the bias. Therefore, to maximize the benefit of the fine vertical resolution RO observations in the lower troposphere for global models, the data assimilation system needs to develop the capability to deal with the singularity problem due to the ducting.

\section{Conclusions and future work}

In this paper, we analyzed the ABL structures in COSMIC GPS RO, radiosondes and ECMWF analysis data over the SE Pacific where the VOCALS campaign took place. The VOCALS radiosonde observations show a well-defined ABL top with a strong temperature inversion and a sharp moisture 
gradient, which produces a sharp refractivity gradient and a large bending angle in the GPS RO signals. The refractivity gradients over the region are often so large that they exceed critical refraction (e.g., $-157 \mathrm{~N}$-unit $\mathrm{km}^{-1}$ ) and become the ducting (or super-refraction) condition. This situation can result in a systematic negative refractivity bias ( $N$-bias) in the standard RO retrieval inside the ABL (Sokolovskiy, 2003; Xie et al., 2006). It is noteworthy that the $N$-bias does not affect the ABL height detected with the MRG method. Instead, the very sharp refractivity gradient caused by ducting allows the best detection of ABL height from GPS RO through the simple MRG method.

The comparison of RO ABL height derived from the MRG method with radiosondes is encouraging, however, ECMWF shows a systematically low bias in the ABL height and the bias becomes larger in the deeper ABL (Fig. 3b). The VOCALS radiosondes exhibit a wide range of ABL height variations $(1 \sim 2 \mathrm{~km})$ in the PDF, with the peak occurrence frequency at $\sim 1.3 \mathrm{~km}$ (Fig. $4 \mathrm{~b}$ ). The vertical smoothing results in a slightly lower ABL height, but does not change the overall shape of the PDF. The near-coincident COSMIC RO captures the wide range of ABL height variations (Fig. 4a, c). ECMWF analysis, on the other hand, tends to produce systematically shallower ABL as compared with both the nearcoincident radiosondes (Fig. 4b) and COSMIC RO soundings (Fig. 4c). The discrepancy between the ECMWF and radiosondes is not due to the limited vertical resolution $(\sim 200$ $\mathrm{m})$ in the model.

The PDF of the radiosonde MRG depends strongly on the vertical resolution of the refractivity profile. The higher order smoothing results in a smaller MRG value. Nearly all the VOCALS radiosonde data have a ducting layer even after 200-m smoothing. The near-coincident ECMWF analysis underestimates the high MRG and overestimates the low MRG as compared to radiosondes after 200-m smoothing. On the other hand, COSMIC RO shows a systematic bias in the MRG and the RO refractivity inside the ABL, which are primarily caused by the non-unique inversion problem in the presence of ducting. The ABL height derived from COSMIC RO is generally not affected by the ducting. However, it would require specific attention for directly using such biased RO refractivity profiles for scientific studies. Simulation study based on radiosonde soundings reveals strong dependence of ducting-induced $N$-bias on vertical resolutions, i.e., higher order smoothing leads to a smaller $N$-bias (Fig. 6). The 100-m smoothing shows the peak frequency of $N$-bias $\sim-12 \%$, which reduces to $\sim-8 \%$ with 200 -m smoothing and decreases further with additional smoothing. ECMWF analysis shows the PDF of $N$-bias comparable to the radiosonde soundings with $\sim 300-\mathrm{m}$ smoothing, but underestimates the ducting occurrence frequency.

Both COSMIC RO and ECMWF analysis clearly show the deepening of the ABL heights westward from the shallow stratocumuli near the coast of Peru and Chile to the much deeper trade wind cumuli. However, the difference in ABL height between ECMWF analysis and COSMIC RO is significant and cannot be ignored. COSMIC RO shows a deeper ABL with a minimum ABL height $(\sim 1.2 \mathrm{~km})$ centered at $\left(20^{\circ} \mathrm{S}, 75^{\circ} \mathrm{W}\right)$, which is located $\sim 10^{\circ}$ north of what is seen in ECMWF analysis. The maximum ABL height $(\sim 2.3 \mathrm{~km})$ from COSMIC RO is centered at $20^{\circ}$ west of ECMWF (Fig. 7). At low latitudes, despite the decreasing number of COSMIC RO soundings and the lower percentage of soundings that penetrate into the lowest 500-ma.m.s.l., there are small sampling errors in the mean ABL height climatology.

The ABL height observed from COSMIC RO provides an extremely valuable and independent dataset for diagnostic analysis of various ABL parameterization schemes in weather and climate models. The biased RO refractivity due to the ducting over the eastern oceans and the trade wind regions (Xie et al., 2010a) would need to be corrected (e.g., Xie et al., 2006) before scientific application. Improving the percentage of RO profiles penetrating into the $\mathrm{ABL}$ and a better understanding of horizontal averaging effect in $\mathrm{RO}$ would further enhance the scientific values of GPS RO soundings for global ABL studies.

Acknowledgements. This work was supported by an appointment to JIFRESSE at UCLA. F. Xie and E. R. Kursinski are partly supported by NOAA JCSDA. D. L. Wu, C. O. Ao and A. J. Mannucci are supported by the Jet Propulsion Laboratory (JPL), California Institute of Technology, under a contract with NASA. The COSMIC RO soundings were provided by JPL. The highresolution ECMWF analysis data were acquired from ECMWF. The VOCALS radiosondes were provided by NCAR/EOL under sponsorship of the National Science Foundation. The rawinsondes from stratus cruises around $20^{\circ} \mathrm{S}$ were provided by deSzoeke at Oregon State University. We thank S. Healy, R. Wood and J. Teixeira for the intriguing discussions. We thank Byron Iijima, Marc Pestana for assistance with the COSMIC retrievals and Evan Fishbein for help with ECMWF data. We also thank Rene Garreaud (editor) and the two reviewers for valuable comments.

Edited by: R. Garreaud

\section{References}

Anthes, R. A., Bernhardt, P. A., Chen, Y., Cucurull, L., Dymond, K. F., Ector, D., Healy, S. B., Ho, S.-P., Hunt, D. C., Kuo, Y.-H., Liu, H., Manning, K., McCormick, C., Meehan, T. K., Randel, W. J., Rocken, C., Schreiner, W. S., Sokolovskiy, S. V., Syndergaard, S., Thompson, D. C., Trenberth, K. E., Wee, T.-K., Yen, N. L., and Zeng, Z.: The COSMIC/FORMOSAT-3 mission: Early results, B. Am. Meteorol. Soc., 89, 313-333, 2008.

Ao, C. O.: Effect of ducting on radio occultation measurements: An assessment based on high-resolution radiosonde soundings, Radio Sci., 42, RS2008, doi:10.1029/2006RS003485, 2007.

Ao, C. O., Meehan, T. K., Hajj, G. A., Mannucci, A. J., and Beyerle, G.: Lower-troposphere refractivity bias in 
GPS occultation retrievals, J. Geophys. Res., 108, 4577, doi:10.1029/2002JD003216, 2003.

Ao, C. O., Chan, T. K., Iijima, B. A., Li, J.-L., Mannucci, A. J., Teixeira, T., Tian, B., and Waliser, D. E.: Planetary boundary layer information from GPS radio occultation measurements, ECMWF GRAS SAF Workshop on Applications of GPS Radio Occultation Measurements (16-18 June 2008), Reading, UK, 123-131, 2008.

Ao, C. O., Hajj, G. A., Meehan, T. K., Dong, D., Iijima, B. A., Mannucci, A. J., and Kursinski, E. R.: Rising and setting GPS occultations by use of open-loop tracking, J. Geophys. Res., 114, D04101, doi:10.1029/2008JD010483, 2009.

Ao, C. O., Waliser, D. E., Li, J.-L., Chan, T. K., Tian, B., and Xie, F.: Planetary boundary layer depths from GPS radio occultation profiles, J. Geophys. Res., submitted, 2012.

Basha, G., and Ratnam, M. V.: Identification of atmospheric boundary layer height over a tropical station using high resolution radiosonde refractivity profiles: Comparison with GPS radio occultation measurements, J. Geophys. Res., 114, D16101, doi:10.1029/2008JD011692, 2009.

Bauer, P., Lopez, P., Benedetti, A., Salmond, D., and Moreau, E.: Implementation of $1 \mathrm{D}+4 \mathrm{D}$-Var assimilation of precipitation affected microwave radiances at ECMWF, Part I: 1D-Var, Q. J. Roy. Meteorol. Soc., 132, 2277-2306, 2006.

Beyerle, G., Schmidt, T., Wickert, J., Heise, S., Rothacher, M., König-Langlo, G., and Lauritsen, K. B.: Observations and simulations of receiver-induced refractivity biases in GPS radio occultation, J. Geophys. Res., 111, D12101, doi:10.1029/2005JD006673, 2006.

Bony, S., and Dufresne J.-L.: Marine boundary layer clouds at the heart of tropical cloud feedback uncertainties in climate models, Geophys. Res. Lett., 32, L20806, doi:10.1029/2005GL023851, 2005.

Bretherton, C. S., Uttal, T., Fairall, C.W., Yuter, S. E.,Weller, R. A., Baumgardner, D., Comstock, K., Wood, R., and Raga, G. B.: The EPIC 2001 stratocumulus study, B. Am. Meteorol. Soc., 85, 967-977, doi:10.1175/BAMS-85-7-967, 2004.

Bretherton, C. S., Wood, R., George, R. C., Leon, D., Allen, G. and Zheng X.: Southeast Pacific stratocumulus clouds, precipitation and boundary layer structure sampled along 20S during VOCALS-Rex, Atmos. Chem. Phys., 10, 10639-10654, doi:10.5194/acp-10-10639-2010, 2010.

Cao, G., Giambelluca, T. W., Stevens, D. E. and Schroeder, T. A.: Inversion Variability in the Hawaiian Trade Wind Regime, J. Climate, 20, 1145-1160, 2007.

Clement, A. C., Burgman R., and Norris J. R.: Observational and model evidence for positive low-level cloud feedback, Science, 325, 460-464, doi:10.1126/science.1171255, 2009.

Cucurull, L., Kuo, Y. H., Barker, D., and Rizvi, S. R. H.: Assessing the impact of simulated COSMIC GPS radio occultation data on weather analysis over the Antarctic: A case study, Mon. Wea. Rev., 134, 3283-3296, 2006.

Cucurull, L., Derber, J. C., Treadon, R., and Purser, R. J.: Assimilation of Global Positioning System radio occultation observations into NCEP's Global Data Assimilation System, Mon. Wea. Rev., 135, 3174-3193, 2007.

de Szoeke, S. P., Fairall, C. W., Wolfe, D. E., Bariteau, L., and Zuidema, P.: Surface Flux Observations on the Southeastern Tropical Pacific Ocean and Attribution of SST Errors in Coupled
Ocean-Atmosphere Models, J. Climate, 23, 4152-4174, 2010.

Deardorff J. W.: On the entrainment rate of a stratocumulus-topped mixed layer, Q. J. Roy. Meteorol. Soc., 102, 563-582, 1976.

Fjeldbo, G., Kliore, A. J., and Eshleman, V. R.: The neutral atmosphere of Venus as studied with the Mariner V radio occultation experiment, Astron. J., 76, 123-140, 1971.

Garay, M. J., de Szoeke, S. P., and Moroney, C. M.: Comparison of marine stratocumulus cloud top heights in the southeastern Pacific retrieved from satellites with coincident ship-based observations, J. Geophys. Res., 113, D18204, doi:10.1029/2008JD009975, 2008.

Gorbunov, M. E., Benzon, H.-H., Jensen, A. S., Lohmann, M. S., and Nielsen, A. S.: Comparative analysis of radio occultation processing approaches based on Fourier integral operators, Radio Sci., 39, RS6004, doi:10.1029/2003RS002916, 2004.

Guo, P., Kuo, Y.-H., Sokolovskiy, S. V., and Lenschow, D. H.: Estimating atmospheric boundary layer depth using COSMIC radio occultation data, J. Atmos. Sci., 68, 1703-1713, 2011.

Hajj, G. A., Kursinski, E. R., Romans, L. J., Bertiger, W. I., and Leroy, S. S.: A technical description of atmospheric sounding by GPS occultation, J. Atmos. Solar Terr. Phys., 64, 451-469, 2002.

Harshvardhan, Zhao, G., Girolamo, Di, L., and Green, R. N.: Satellite-observed location of stratocumulus cloud-top heights in the presence of strong inversions, IEEE Trans. Geosci. Remote Sens., 47, 1421-1428, doi:10.1109/TGRS.2008.2005406, 2009.

Healy, S. and Thépaut, J.-N.: Assimilation experiments with CHAMP GPS radio occultation measurements, Q. J. Roy. Meteorol. Soc., 132, 605-623, 2006.

Healy, S. B.: Assimilation of GPS radio occultation measurements at ECMWF, Proceedings of the GRAS SAF Workshop on Applications of GPSRO measurements, ECMWF, Reading, UK, 1618 June 2008, 99-109, 2008.

Ho, S.-P., Kirchengast, G., Leroy, S., Wickert, J.; Mannucci, A. J., Stiner, A. K., Hunt, D., Schreiner, W., Sokolovskiy, S., Ao, C. O., Borsche, M., von Engeln, A., Foelsche, U., Heise, S., Iijima, B., Kuo, Y.-H., Kursinski, R., Pirscher, B., Ringer, M., Rocken, C., and Schmidt, T.: Estimating the uncertainty of using GPS radio occultation data for climate monitoring: Intercomparison of CHAMP refractivity climate records from 2002 to 2006 from different data centers, J. Geophys. Res., 114, D23107, doi:10.1029/2009JD011969, 2009.

Jordan, N. S., Hoff, R. M., and Bacmeister, J. T.: Validation of Goddard Earth Observing System-version 5 MERRA planetary boundary layer heights using CALIPSO, J. Geophys. Res., 115, D24218, doi:10.1029/2009JD013777, 2010.

Klein, S. A. and Hartmann, D. L.: The seasonal cycle of low stratiform clouds, J. Climate, 6, 1587-1606, 1993.

Kursinski, E. R., Hajj, G. A., Schofield, J. T., Linfield, R. P., and Hardy, K. R.: Observing Earth's atmosphere with radio occultation measurements using the Global Positioning System, J. Geophys. Res., 102, 23429-23465, 1997.

Lilly, D. K.: Models of cloud topped mixed layers under a strong inversion, Q. J. Roy. Meteorol. Soc., 94, 292-309, 1968.

Lopez, P.: A 5-yr 40-km-Resolution Global Climatology of Superrefraction for Ground-Based Weather Radars, J. Appl. Meteorol. Clim., 48, 89-110, 2009.

Ma, C.-C., Mechoso, C. R., Robertson, A. W., and Arakawa, A.: Peruvian stratus clouds and the tropical Pacific circulation: A coupled ocean-atmosphere GCM study, J. Climate, 9, 1635-1645, 
1996.

Palm, S. P., Benedetti, A., and Spinhirne, J.: Validation of ECMWF global forecast model parameters using GLAS atmospheric channel measurements, Geophys. Res. Lett., 32, L22S09, doi:10.1029/2005GL023535, 2005.

Pirscher, B., Foelsche, U., Borsche, M., Kirchengast, G., and Kuo, Y.-H.: Analysis of migrating diurnal tides detected in FORMOSAT-3/COSMIC temperature data, J. Geophys. Res., 115, D14108, doi:10.1029/2009JD013008, 2010.

Poli, P., Healy, S. B., and Dee, D. P.: Assimilation of global positioning system ratio occultation data in the ECMWF ERAInterim reanalysis, Q. J. Roy. Meteorol. Soc. 136, 1972-1990, doi:10.1002/qj.722, 2010.

Rahn, D. A. and Garreaud, R.: Marine boundary layer over the subtropical southeast Pacific during VOCALS-REx - Part 1: Mean structure and diurnal cycle, Atmos. Chem. Phys., 10, 4491-4506, doi:10.5194/acp-10-4491-2010, 2010.

Randall, D. A., Coakley, J. A., Lenschow, D. H., Fairall, C. W., and Kropfli, R. A.: Outlook for Research on Subtropical Marine Stratification Clouds, B. Am. Meteorol. Soc., 65, 1290-1301, 1984.

Randall, D., Curry, J., Battisti, D., Flato, G., Grumbine, R., Hakkinen, S., Martinson, D., Preller, R., Walsh, J., and Weatherly, J.,: Status and outlook for large scale modeling of atmosphere-iceocean interactions in the Arctic, B. Am. Meteorol. Soc., 79, 197219, 1998

Seidel D., Ao, C. O., and Li, K.: Estimating climatological planetary boundary layer heights from radiosonde observations: Comparison of methods and uncertainty analysis, J. Geophys. Res., 115, D16113, doi:10.1029/2009JD013680, 2010.

Slingo, A.: Sensitivity of the earth's radiation budget to changes in the low clouds, Nature, 343, 49-51, 1990.

Smith, E. K. and Weintraub, S.: The constants in the equation for atmospheric refractive index at radio frequencies, Proc. Inst. Radio Engrs., 41, 1035-1037, 1953.

Sokolovskiy, S. V.: Tracking tropospheric radio occultation signals from low Earth orbit, Radio Sci., 36, 483-498, 2001.

Sokolovskiy, S. V.: Effect of superrefraction on inversions of radio occultation signals in the lower troposphere,Radio Sci., 38, 1058, doi:10.1029/2002RS002728, 2003.

Sokolovskiy, S., Kuo, Y.-H., Rocken, C., Schreiner, W. S., Hunt, D., and Anthes, R. A.: Monitoring the atmospheric boundary layer by GPS radio occultation signals recorded in the open-loop mode, Geophys. Res. Lett., 33, L12813, doi:10.1029/2006GL025955, 2006.

Sokolovskiy, S. V., Rocken, C., Lenschow, D. H., Kuo, Y.-H., Anthes, R. A., Schreiner, W. S. and Hunt, D. C.: Observing the moist troposphere with radio occultation signals from COSMIC, Geophys. Res. Lett., 34, L18802, doi:10.1029/2007GL030458, 2007.

Toniazzo, T., Abel, S. J., Wood, R., Mechoso, C. R., Allen, G., and Shaffrey, L. C.: Large-scale and synoptic meteorology in the south-east Pacific during the observations campaign VOCALSREx in austral Spring 2008, Atmos. Chem. Phys., 11, 49775009, doi:10.5194/acp-11-4977-2011, 2011.

von Engeln, A. and Teixeira, J.: A ducting climatology derived from the European Centre for Medium-Range Weather Forecasts global analysis fields, J. Geophys. Res., 109, D18104, doi:10.1029/2003JD004380, 2004. von Engeln, A. and Teixeira J.: A planetary boundary layer height climatology derived from ECMWF Re-analysis data, J. Appl. Meteorol. Clim., submitted, 2011.

Wang, J., Rossow, W. B., Uttal, T., and Rozendaal, M.: Variability of cloud vertical structure during ASTEX observed from a combination of rawinsonde, radar, ceilometer and satellite, Mon. Weather Rev. 127, 2484-2502, 1999.

Wang, S., O’Neill, L. W., Jiang, Q., de Szoeke, S. P., Hong, X., Jin, H., Thompson, W. T., and Zheng, X.: A regional real-time forecast of marine boundary layers during VOCALS-REx, Atmos. Chem. Phys., 11, 421-437, doi:10.5194/acp-11-421-2011, 2011.

Wood, R. and Bretherton, C. S.: Boundary layer depth, entrainment and decoupling in the cloud-capped subtropical and tropical marine boundary layer, J. Clim., 17, 3576-3588, 2004.

Wood, R., Bretherton, C. S., Mechoso, C. R., Weller, R. A., Huebert, B., Straneo, F., Albrecht, B. A., Coe, H., Allen, G., Vaughan, G., Daum, P., Fairall, C., Chand, D., Gallardo Klenner, L., Garreaud, R., Grados Quispe, C., Covert, D. S., Bates, T. S., Krejci, R., Russell, L. M., de Szoeke, S., Brewer, A., Yuter, S. E., Springston, S. R., Chaigneau, A., Toniazzo, T., Minnis, P., Palikonda, R., Abel, S. J., Brown, W. O. J., Williams, S., Fochesatto, J., and Brioude, J.: The VAMOS Ocean-CloudAtmosphere-Land Study Regional Experiment (VOCALS-REx) : goals, platforms, and field operations, Atmos. Chem. Phys., 11, 627-654, doi:10.5194/acp-11-627-2011, 2011.

Wu, D., Hu, Y., McCormick, M., Xu, K., Liu, Z., Smith, B., Omar, A., and Chang, F.: Deriving marine-boundary-layer lapse rate from collocated CALIPSO, MODIS, and AMSR-E data to study global low-cloud height statistics, Geosci. Remote Sens. Lett., 5, 649-652, 2008.

Wyant, M. C., Wood, R., Bretherton, C. S., Mechoso, C. R., Bacmeister, J., Balmaseda, M. A., Barrett, B., Codron, F., Earnshaw, P., Fast, J., Hannay, C., Kaiser, J. W., Kitagawa, H., Klein, S. A., Köhler, M., Manganello, J., Pan, H.-L., Sun, F., Wang, S., and Wang, Y.: The PreVOCA experiment: modeling the lower troposphere in the Southeast Pacific, Atmos. Chem. Phys., 10, 4757-4774, doi:10.5194/acp-10-4757-2010, 2010.

Xie, F.: Development of a GPS occultation retrieval method for characterizing the marine boundary layer in the presence of super-refraction, Dissertation, University of Arizona, USA, 134 pp., 2006.

Xie, F., Syndergaard, S., Kursinski, E. R., and Herman, B. M.: An Approach for Retrieving Marine Boundary Layer Refractivity from GPS Occultation Data in the Presence of Super-refraction, J. Atmos. Ocean Tech, 23, 1629-1644, 2006.

Xie, F., Wu, D. L., Ao, C. O., Kursinski, E. R., Mannucci, A. and Syndergaard, S.: Super-refraction effects on GPS radio occultation refractivity in marine boundary layers, Geophys. Res. Lett., 37, L11805, doi:10.1029/2010GL043299, 2010a.

Xie, F., Wu, D. L., Ao, C. O., and Mannucci, A. J.: Atmospheric diurnal variations observed with GPS radio occultation soundings, Atmos. Chem. Phys., 10, 6889-6899, doi:10.5194/acp-10-68892010, 2010b.

Zeng, X., Brunke, M. A., Zhou, M., Fairall, C., Bond, N. A., and Lenschow, D. H.: Marine atmospheric boundary layer height over the eastern Pacific: data analysis and model evaluation. J. Climate, 17, 4159-4170, 2004. 
Zuidema, P., Painemal, D., de Szoeke, S., and Fairall, C.: Stratocumulus cloud-top height estimates and their climatic implications, J. Climate, 22, 4652-4666, 2009. 